\title{
Flavones from the Leaves of Ficus gomelleira
}

\author{
Daniel F. Amaral, Mara S. P. Arruda*, Alberto C. Arruda, Adolfo H. Müller, \\ Luna L. J. Pantoja and Tânia M. da S. Lima
}

\author{
Departamento de Química, Centro de Ciências Exatas e Naturais, Universidade Federal do Pará, \\ Campus Universitário, 66075-970, Belém - PA, Brazil
}

\begin{abstract}
Duas novas flavonas, 5-hidroxi-7,5' -dimetoxi-3',4'-metilenodioxiflavona e 5-hidroxi-7,3',5'trimetoxi-4'-(3,3-dimetilaliloxi)flavona foram isoladas das folhas de Ficus gomelleira, juntamente com três flavonas conhecidas, a 5,6,7,3',4',5'-hexametoxiflavona, 5-hidroxi-8,3',4'-trimetoxi$2^{\prime \prime}, 2^{\prime \prime}$-dimetilpirano (5",6":6,7)-flavona e 5-hidroxi-8,3',4',5'-tetrametoxi-2", 2"-dimetilpirano (5",6":6,7)-flavona. As estruturas das substâncias isoladas foram elucidadas com base na análise de seus dados espectrais, bem como por comparação com dados da literatura.
\end{abstract}

Two new flavones, 5-hydroxy-7,5'-dimethoxy-3',4'-methylenedioxyflavone and 5-hydroxy7,3',5'-trimethoxy-4'-(3,3-dimethylallyloxy)flavone, as well as three known flavones: $5,6,7,3^{\prime}, 4$ ' , 5'-hexamethoxyflavone, 5-hydroxy-8, 3',4'-trimethoxy-2",2"-dimethylpyrano (5",6":6,7)-flavone and 5-hydroxy-8,3', 4',5'-tetramethoxy-2",2"-dimethylpyrano (5",6":6,7)flavone were isolated from the leaves of Ficus gomelleira. Their structures were elucidated by spectroscopic methods and comparison with literature data.

Keywords: Ficus gomelleira, Moraceae, leaves, flavones

\section{Introduction}

In the course of our systematic studies on the species of genus Ficus of medicinal interest, which grows in the Amazon forest, we have investigated $F$. gomelleira. The leaves and latex of this species are used in folk medicine for intestinal diseases as laxative and vermifuge ${ }^{1}$. Earlier studies on the genus Ficus (F. maxima and F. aripuanensis), carried out in our laboratory, have resulted in the isolation of flavonoids and terpenoids 2,3 . From $F$. gomelleira two novel flavones, 5-hydroxy-7, $5^{\prime}$-dimethoxy-3', $4^{\prime}$-methylenedioxyflavone (1) and 5-hydroxy-7,3', 5' -trimethoxy-4'-(3,3dimethylallyloxy)flavone (2) were obtained, and the known flavones 5,6,7,3',4',5'-hexamethoxyflavone $(\mathbf{3})^{4}$, 5-hydroxy$8,3^{\prime}, 4^{\prime}$-trimethoxy-2", $2^{\prime \prime}$-dimethylpyrano (5",6":6,7)-flavone (4) ${ }^{5}$ and 5-hydroxy-8, $3^{\prime}, 4^{\prime}, 5^{\prime}$-tetramethoxy-2", $2^{\prime \prime}$-dimethylpyrano $\left(5^{\prime \prime}, 6^{\prime \prime}: 6,7\right)$-flavone $(5)^{6}$. In this paper we describe the isolation and structural elucidation of $\mathbf{1}$ and $\mathbf{2}$.

\section{Experimental}

\section{General experimental procedures}

IR spectra were taken on a Perkin Elmer 281 Spectrometer. ${ }^{1} \mathrm{H}$ NMR (300 and $500 \mathrm{MHz}$ ) and ${ }^{13} \mathrm{C}$ NMR (75 and 125
$\mathrm{MHz}$ ) spectra were recorded on a Varian GEMINI 300 and a Bruker DRX 500, in $\mathrm{CDCl}_{3}$, with residual solvent peak as int. reference. The MS runs were performed using a Micromass Platform II instrument (Micromass, Wythenshawe, Manchester, UK) equipped with an EI/CI ion source. Electrospray and CAD data were collected in a triple quadrupole Micromass Quatro LC instrument (Micromass, Wythenshawe, Manchester, UK) equipped with a "Z-spray" ion source. Chromatography was performed using silica gel (Merck) for column and preparative TLC. The purity of the compounds was checked by ${ }^{1} \mathrm{H}$ and ${ }^{13} \mathrm{C}$ NMR spectral analysis and TLC plate, revealed with UV (254 nm) and ceric sulphate $(0.2 \%)$ in $\mathrm{H}_{2} \mathrm{SO}_{4}(5 \%)$.

\section{Plant material}

Leaves of $F$. gomelleira were collected in Marituba County, State of Pará, Brazil. Voucher specimen n ${ }^{\circ} 0147615$ has been deposited at the Herbarium of the Emílio Goeldi Museum, Department of Botany, Belém, Pará, Brazil.

\section{Extraction and isolation of flavones}

The ground dried leaves $(3.0 \mathrm{~kg})$ were extracted at room temperature with hexane and $\mathrm{CH}_{2} \mathrm{Cl}_{2}$, successively. The hexane extract (11.0 g) was chromatographed on silica gel and eluted 
<smiles>COc1cc(O)c2c(=O)cc(-c3cc(OC)c4c(c3)OCO4)oc2c1</smiles><smiles>COc1cc(O)c2c(=O)cc(-c3cc(OC)c(O[I+]C=C(C)C)c(OC)c3)oc2c1</smiles><smiles>C#Cc1cc(OC)c2c(c1)OCO2</smiles><smiles>COc1cc(C#[Co+])cc2c1OCO2</smiles><smiles>COc1cc(-c2cc(=O)c3c(OC)c(OC)c(OC)cc3o2)cc(OC)c1OC</smiles><smiles>COc1ccc(-c2cc(=O)c3c(O)c4c(c(OC)c3o2)OC(C)(C)C=C4)cc1OC</smiles><smiles>COc1cc(-c2cc(=O)c3c(O)c4c(c(OC)c3o2)OC(C)(C)C=C4)cc(OC)c1OC</smiles>

with a gradient of acetone in hexane to give 20 fractions. Fr. 10 eluted with hexane-acetone (9:1) was purified by repeated column chromatography on silica gel with hexane- $\mathrm{CH}_{2} \mathrm{Cl}_{2}$ acetone mixtures of increasing polarity, followed by prep. TLC (silica gel, hexane-EtOAc 9:1, 5 runs) to give 2 (3 mg). Fr. 17 eluted with hexane-acetone $(8: 2)$ was submitted to repeated $\mathrm{CC}$ on silica gel with of hexane- $\mathrm{CHCl}_{3}$-EtOAc mixtures, followed by prep. TLC (silica gel, developed with $\mathrm{CHCl}_{3}, 3$ runs) to yield $\mathbf{3}$ (10 $\mathrm{mg}$ ).

The dichloromethane extract (29.0 g) was subjected to $\mathrm{CC}$ on silica gel and eluted with hexane- $\mathrm{CH}_{2} \mathrm{Cl}_{2}-\mathrm{MeOH}$ mixtures of increasing polarity affording 47 fractions. Fr. 22 eluted with hexane- $\mathrm{CH}_{2} \mathrm{Cl}_{2}$ (6:4) was purified twice by $\mathrm{CC}$ on silica gel with mixtures of hexane- $\mathrm{CHCl}_{3}-\mathrm{MeOH}$ affording 1 (9 mg). Fr. 28 eluted with hexane- $\mathrm{CH}_{2} \mathrm{Cl}_{2}$ (1:1) was separated by repeated $\mathrm{CC}$ on silica gel with mixtures of hexane$\mathrm{CH}_{2} \mathrm{Cl}_{2}$-acetone of increasing polarity affording 5 (16 mg). Fr. 29 eluted with hexane- $\mathrm{CH}_{2} \mathrm{Cl}_{2}$ (4:6) was purified after repeated $\mathrm{CC}$ on silica gel with mixtures of hexane- $\mathrm{CHCl}_{3}$ acetone, followed by prep. TLC (silica gel, hexane-EtOAc $7: 3,3$ runs) to yield $4(6 \mathrm{mg})$. The identification of the known compounds 3-5 involved the analysis of ${ }^{1} \mathrm{H}$ and ${ }^{13} \mathrm{C}$ NMR spectral data and comparison with literature values ${ }^{4-6}$.

5-hydroxy-7,5'-dimethoxy-3',4'-methylenedioxyflavone (1). Brown oil. UV $\lambda_{\max } / \mathrm{nm}(\mathrm{MeOH})(\log \varepsilon): 260$ (3.32), 332 (3.09), $380 \mathrm{sh}$ (2.98); UV $\lambda_{\max } / \mathrm{nm}(\mathrm{MeOH}+$ $\mathrm{AlCl}_{3}$ ) (log $\varepsilon$ ): 257 (3.50), 340 (3.06), 380 sh (2.98); UV $\lambda_{\max } / \mathrm{nm}\left(\mathrm{MeOH}+\mathrm{AlCl}_{3}+\mathrm{HCl}\right)(\log \varepsilon): 254$ (3.60), 341 (3.09), $381 \mathrm{sh}$ (2.99). IR $v_{\max } / \mathrm{cm}^{-1} 3405,1655,1601,1491$, 1447, 1164, 1045 (film). ${ }^{1} \mathrm{H}$ and ${ }^{13} \mathrm{C}$ NMR see Table 1;

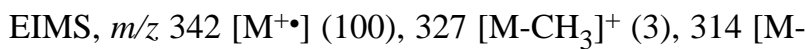
$\mathrm{CO}^{+\bullet}$ (8), 312 (13), 299 (13), 179 (5), 176 (19), 166 (5).

5-hydroxy-7,3',5'-trimethoxy-4'-(3,3-dimethylallyloxy)flavone (2). Brown oil. UV $\lambda_{\max } / n m(\mathrm{MeOH})(\log$ ع): 245 (3.97), 333 (3.98), 380 sh (3.43); UV $\lambda_{\max } / \mathrm{nm}$ $\left(\mathrm{MeOH}+\mathrm{AlCl}_{3}\right)(\log \varepsilon): 277$ (4.09), 348 (3.98), $385 \mathrm{sh}$ (3.89); $\mathrm{UV} \lambda_{\max } / \mathrm{nm}\left(\mathrm{MeOH}+\mathrm{AlCl}_{3}+\mathrm{HCl}\right)(\log \varepsilon): 275$ (4.23), 345 (3.97), $380 \mathrm{sh}$ (3.87); IR $v_{\max } / \mathrm{cm}^{-1} 3410,2920$, 1648, 1605, 1488, 1447, 1340, 1251, 1116 (film); ${ }^{1} \mathrm{H}$ and ${ }^{13} \mathrm{C}$ NMR see Table 1; ESIMS, $m / z 413[\mathrm{M}+\mathrm{H}]^{+}(29), 385$ $[\mathrm{M}+\mathrm{H}-\mathrm{CO}]^{+}(7), 371(28), 345\left[\mathrm{M}+\mathrm{H}-\mathrm{C}_{5} \mathrm{H}_{8}\right]^{+}(100), 329$ (29), 301 (30), 298 (9), 171 (14). 
Table 1. ${ }^{1} \mathrm{H}(300 \mathrm{MHz})$ and ${ }^{13} \mathrm{C}(75 \mathrm{MHz}) \mathrm{NMR}$ spectral data for $\mathbf{1}$ and $\mathbf{2}$ in $\mathrm{CDCl}_{3}$. Chemical shifts in $\delta\left(\delta_{\mathrm{H}}\right.$ and $\delta_{\mathrm{C}}$, ppm) and coupling constants $(J$, in parentheses) in Hz.*

\begin{tabular}{|c|c|c|c|c|}
\hline & \multicolumn{2}{|c|}{$\mathbf{1}$} & \multicolumn{2}{|c|}{2} \\
\hline & $\delta_{\mathrm{C}}$ & $\delta_{\mathrm{H}}$ & $\delta_{\mathrm{C}}$ & $\delta_{\mathrm{H}}$ \\
\hline \multicolumn{5}{|l|}{$\mathbf{C}$} \\
\hline 2 & 163.5 & & 163.9 & \\
\hline 4 & 182.4 & & 182.3 & \\
\hline 5 & 162.2 & & 162.3 & \\
\hline 7 & 165.6 & & 165.6 & \\
\hline 9 & 157.7 & & 157.6 & \\
\hline 10 & 105.2 & & 105.6 & \\
\hline $1^{\prime}$ & 125.7 & & 126.4 & \\
\hline $3^{\prime}$ & 149.6 & & 154.1 & \\
\hline $4^{\prime}$ & 138.6 & & 140.6 & \\
\hline $5^{\prime}$ & 143.9 & & 154.1 & \\
\hline 3" & & & 139.4 & \\
\hline \multicolumn{5}{|l|}{$\mathbf{C H}$} \\
\hline 3 & 105.2 & $6.54(\mathrm{~s})$ & 105.6 & $6.60(\mathrm{~s})$ \\
\hline 6 & 98.2 & $6.37(\mathrm{~d}, 2.3)$ & 98.2 & $6.38(\mathrm{~d}, 2.1)$ \\
\hline 8 & 92.7 & $6.48(\mathrm{~d}, 2.3)$ & 92.7 & $6.50(\mathrm{~d}, 2.1)$ \\
\hline $2^{\prime}$ & 107.3 & $7.06(\mathrm{~d}, 1.4)$ & 103.8 & $7.07(\mathrm{~s})$ \\
\hline 6 & 100.7 & $7.09(\mathrm{~d}, 1.4)$ & 103.8 & 7.07 (s) \\
\hline $2 "$ & & & 120.3 & $5.56(\mathrm{t}, 7.2)$ \\
\hline \multicolumn{5}{|l|}{$\mathrm{CH}_{2}$} \\
\hline $1 "$ & & & 69.7 & $4.58(\mathrm{~d}, 7.2)$ \\
\hline \multicolumn{5}{|l|}{$\mathrm{CH}_{3}$} \\
\hline MeO-7 & 56.82 & $3.88(\mathrm{~s})$ & 55.8 & $3.84(\mathrm{~s})$ \\
\hline MeO-3' & & & 56.4 & $3.94(\mathrm{~s})$ \\
\hline MeO-5' & 56.97 & $3.99(\mathrm{~s})$ & 56.4 & $3.94(\mathrm{~s})$ \\
\hline 4" & & & 25.8 & $1.75(\mathrm{~s})$ \\
\hline $5 "$ & & & 17.9 & $1.68(\mathrm{~s})$ \\
\hline $\mathrm{HO}-5$ & & $12.70(\mathrm{~s})$ & & $12.74(\mathrm{~s})$ \\
\hline
\end{tabular}

\section{Results and Discussion}

Compound 1 was isolated as a brown oil and its molecular formula determined as $\mathrm{C}_{18} \mathrm{H}_{14} \mathrm{O}_{7}$ from NMR and mass spectral data. The UV spectral data indicated that it was a 5hydroxyflavone ${ }^{7}$. The chelated hydroxyl hydrogen at $\delta_{\mathrm{H}} 12.70$ and the carbonyl group at $\delta_{\mathrm{C}} 182.4$ were also consistent with a 5-hydroxyflavone ${ }^{7,8}$. The aromatic region of the ${ }^{1} \mathrm{H}$ NMR spectrum (Table 1) displayed five hydrogen resonance signals $\left[\delta_{\mathrm{H}} 7.06\right.$ and 7.09 (d each, $J 1.4 \mathrm{~Hz}$ ), 6.37 and 6.48 (d each, $J$ $2.3 \mathrm{~Hz}$ ), and $6.54(\mathrm{~s})]$ which constitute two AB spin systems and an isolated hydrogen. These spectral data were in agreement with a 5,7,3', 4',5'-substituted flavone ${ }^{7}$. In addition to a methylenedioxy signal at $\delta_{\mathrm{H}} 6.08$, two aromatic methoxyl resonances were observed at $\delta_{\mathrm{H}} 3.88$ and 3.99. The fragment peaks at $\mathrm{m} / z 176$ (1a) from a retro-Diels-Alder reaction in the EIMS and $m / z 179$ (1b) from a retro-Diels-Alder reaction, followed by a rearrangement, were consistent with the ring $B$ substituted with methylenedioxy and methoxy groups at 3', $4^{\prime}$ and $5^{\prime}$ positions, respectively. As a consequence the ring $\mathrm{A}$ was substituted with the remaining methoxyl at C-7 and $\mathbf{1}$ was determined as 5-hydroxy-7, $5^{\prime}$ - dimethoxy-3', $4^{\prime}$ methylenedioxyflavone. The proposed structure of $\mathbf{1}$ was further confirmed by ${ }^{13} \mathrm{C}$ NMR data (Table 1 ). The correct chemical shifts assignment of all hydrogen $\left(\delta_{\mathrm{H}}\right)$ and carbon $\left(\delta_{\mathrm{C}}\right)$ atoms of 1 was obtained using a combination of HETCOR $\left({ }^{13} \mathrm{C} \mathrm{x}{ }^{1} \mathrm{H}-\mathrm{COSY},{ }^{1} \mathrm{~J}(\mathrm{CH})\right.$; Table 1$), \mathrm{HMBC}\left({ }^{1} \mathrm{H} \mathrm{x}{ }^{13} \mathrm{C}-\mathrm{COSY}\right.$, 2,3 $\mathrm{J}(\mathrm{CH})$; Figure 1) and NOESY $\left({ }^{1} \mathrm{H} \mathrm{x}{ }^{1} \mathrm{H}\right.$ nOe dipolar interaction; Figure 1) experiments. Therefore, for example, the spin-spin interactions of OH-5 $\left(\delta_{\mathrm{H}} 12.7\right)$ with $\mathrm{C}-5\left(\delta_{\mathrm{C}}\right.$ $\left.162.2,{ }^{2} J(\mathrm{CH})\right), \mathrm{C}-6\left(\delta_{\mathrm{C}} 98.2,{ }^{3} J(\mathrm{CH})\right)$ and $\mathrm{C}-10\left(\delta_{\mathrm{C}} 105.2\right.$, ${ }^{3} J(\mathrm{CH})$ ), observed in the HMBC spectrum (Figure 1), have allowed the unequivocal assignment of $\delta_{\mathrm{C}}$ for C-5, C-6 and $\mathrm{C}-10$. Based on the attribution of C-6 along with a heteronuclear direct one bond coupling between $\mathrm{C}-6\left(\delta_{\mathrm{C}} 98.2\right)$ and $\mathrm{H}-6\left(\delta_{\mathrm{H}} 6.37\right)$ revealed by the HETCOR spectrum, it was possible to establish the unequivocal chemical shift of H-6. As a consequence, the other meta-coupled hydrogen $\mathrm{H}-8$ was attributed at $\delta_{\mathrm{H}} 6.48$. The OMe group at position 7 was assigned at $\delta_{\mathrm{H}} 3.88$, based on the ${ }^{1} \mathrm{H} \mathrm{x}{ }^{1} \mathrm{H}$ - NOESY spectrum (Figure 1) which showed the dipolar interactions between $\mathrm{CH}_{3} \mathrm{O}-7\left(\delta_{\mathrm{H}} 3.88\right)$ and both $\mathrm{H}-6\left(\delta_{\mathrm{H}} 6.37\right)$ and $\mathrm{H}-8\left(\delta_{\mathrm{H}} 6.48\right)$, and by cross peak of $\mathrm{CH}_{3} \mathrm{O}-7\left(\delta_{\mathrm{H}} 3.88\right)$ and $\mathrm{H}-8\left(\delta_{\mathrm{H}} 6.48\right)$ with $\mathrm{C}-7\left(\delta_{\mathrm{C}} 165.6,{ }^{2,3} \mathrm{~J}(\mathrm{CH})\right)$, exhibited in the HMBC spectrum. H-2' and H-6' showed doublets at $\delta_{\mathrm{H}} 7.06$ and 7.09, respectively. Their assignments were accomplished by the analysis of the NOESY spectrum, which showed a dipolar interaction between $\mathrm{CH}_{3} \mathrm{O}-5^{\prime}\left(\delta_{\mathrm{H}} 3.99\right)$ and $\mathrm{H}-6{ }^{\prime}\left(\delta_{\mathrm{H}} 7.09\right)$. 

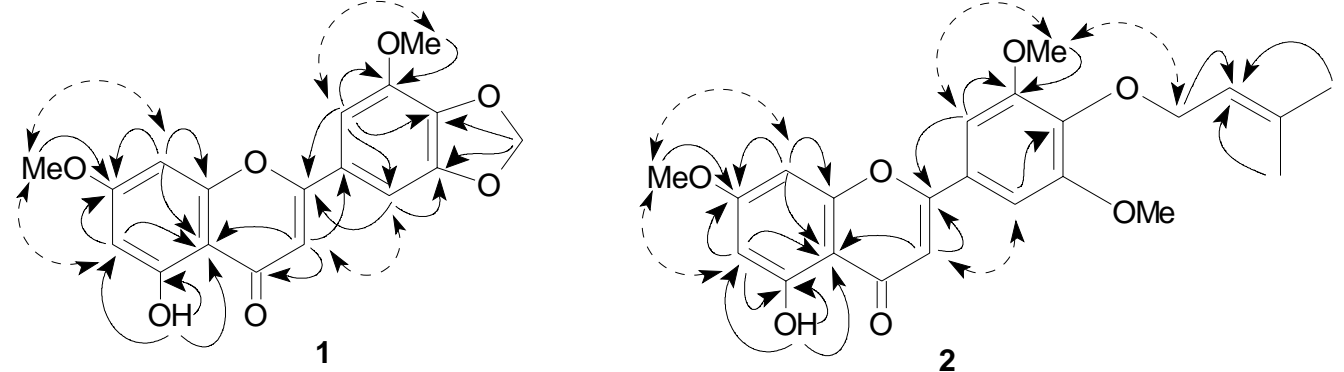

Figure 1. Observed $\mathrm{CH}$ long-range correlations in the $\mathrm{HMBC}(\rightarrow)$ and ${ }^{1} \mathrm{Hx}{ }^{1} \mathrm{H}-\mathrm{NOESY}(\leftrightarrow)$ spectra for $\mathbf{1}$ and $\mathbf{2},\left(500 \mathrm{MHz}, \mathrm{CDCl}_{3}\right)$

The carbon C-4' is between two oxygenated positions, so it was attributed to the signal at $\delta_{\mathrm{C}} 138.6$. The $\delta$ of the other oxygenated carbon atoms $\mathrm{C}-3^{\prime}$ and $\mathrm{C}-5^{\prime}$ were confirmed by the analysis of the $\mathrm{HMBC}$ spectrum, which revealed the cross peaks of $\mathrm{OCH}_{2} \mathrm{O}\left(\delta_{\mathrm{H}} 6.08\right)$ with $\mathrm{C}-3{ }^{\prime}\left(\delta_{\mathrm{C}} 149.6,{ }^{3} J(\mathrm{CH})\right)$ and between H-6' $\left(\delta_{\mathrm{H}} 7.09\right)$ and $\mathrm{CH}_{3} \mathrm{O}-5$ ' $\left(\delta_{\mathrm{H}} 3.99\right)$ with C-5' $\left(\delta_{\mathrm{C}}\right.$ $143.9,2,3 J(\mathrm{CH}))$. These data are also in agreement with those reported for the model compounds 5,4'-dihydroxy-7methoxyflavone ${ }^{8}$ and 5,6,7,8,5'-pentamethoxy-3', $4^{\prime}$ methylenedioxy-flavone ${ }^{9}$.

Compound 2 was isolated as a brown oil and its molecular formula was determined as $\mathrm{C}_{23} \mathrm{H}_{24} \mathrm{O}_{7}$ from the NMR and electronspray ionization (ESI) mass spectra. The UV spectral pattern, including applications of shift reagents (see Experimental) and the chelated hydroxyl proton signal at $\delta_{\mathrm{H}} 12.74$ indicated that 2 was also a 5 -hydroxyflavone ${ }^{7}$. The ${ }^{1} \mathrm{H}$ NMR (Table 1 ) of this compound exhibited signals for three aromatic methoxy groups at $\delta_{\mathrm{H}} 3.84(3 \mathrm{H})$ and 3.94 $(6 \mathrm{H})$, one prenyloxy moiety $\left[\delta_{\mathrm{H}} 4.58\left(\mathrm{~d}, J 7.2 \mathrm{~Hz}, 2 \mathrm{H}-1^{\prime \prime}\right.\right.$, $5.56\left(\mathrm{t}, J 7.2 \mathrm{~Hz}, \mathrm{H}-2^{\prime \prime}, 1.75\left(\mathrm{~s}, 3 \mathrm{H}-4^{\prime \prime}\right)\right.$ and 1.68 $\left.\left(\mathrm{s}, 3 \mathrm{H}-5^{\prime \prime}\right)\right]$ and showed a substitution pattern of ring A identical to compound 1, with two meta-coupled doublets (each $J 2.1 \mathrm{~Hz}$ ) at $\delta_{\mathrm{H}} 6.38$ and 6.50, assigned to $\mathrm{H}-6$ and $\mathrm{H}$ 8 , respectively. The presence of a singlet at $\delta_{\mathrm{H}} 7.07(2 \mathrm{H})$ assigned to $\mathrm{H}-2^{\prime} / 6^{\prime}$ clearly indicated that ring $\mathrm{B}$ was symmetrically substituted with methoxyl groups at $3^{\prime}$ and $5^{\prime}$ positions. The ${ }^{13} \mathrm{C}$ NMR spectrum (Table 1 ) showed signals for methoxyl groups at $\delta_{\mathrm{C}} 55.8$ and 56.4 indicating the absence of methoxyl groups ortho-disubstituted ${ }^{8}$, which implied that the remaining methoxyl was located at C-7 and the prenyloxy group, at $\mathrm{C}-4^{\prime}$. This was supported by NOE interactions between OMe-7 $\left(\delta_{\mathrm{H}} 3.84\right)$ and both $\mathrm{H}-6\left(\delta_{\mathrm{H}}\right.$ $6.38)$ and $\mathrm{H}-8\left(\delta_{\mathrm{H}} 6.50\right)$, as well as between $2 \mathrm{H}-1$ " $\left(\delta_{\mathrm{H}} 4.58\right)$ and OMe-3'/OMe-5' $\left(\delta_{\mathrm{H}} 3.94\right)$ observed in the ${ }^{1} \mathrm{H} \times{ }^{1} \mathrm{H}-$ NOESY spectrum (Figure 1). The above data led us to formulate the new flavone 2 as 5-hydroxy-7,3',5'-trimethoxy4'-(3,3-dimethylallyloxy)flavone. The proposed structure 2 was also in agreement with the ${ }^{13} \mathrm{C}$ NMR data (Table 1), which were fully assigned using a combination of HETCOR,
HMBC and NOESY experiments, as summarized in Table 1 and Figure 1, similarly to what was done with the ${ }^{13} \mathrm{C}$ NMR data of $\mathbf{1}$. These results were also coherent with the data described in the literature for the model compounds $5,4^{\prime}$-dihydroxy-7-methoxyflavone ${ }^{8}$ and 5,6,7,3',5' pentamethoxy-4'-(3,3-dimethylallyloxy)flavone ${ }^{2}$.

\section{Acknowledgements}

The authors are grateful to the Chemistry Department of UFSCar, São Carlos, Brazil for the EIMS and ESIMS spectra and to the Chemistry Department of UFC, Fortaleza, Brazil for the NOESY and HMBC spectra. We also thank the Emílio Goeldi Museum, Pará, Brazil for the plant identification and $\mathrm{CNPq}$ and CAPES Brazilian agencies for the financial support.

\section{References}

1. Carauta, J. P. P. Albertoa 1986, 2, 98.

2. Gaspar, D. M.; Arruda, A. C.; Arruda, M. S. P.; Müller, A. H. Phytochemistry 1997, 45, 1697.

3. Nascimento, M.; Arruda, A. C.; Arruda, M. S. P.; Müller, A. H.; Yoshioka, C. Y. Fitoterapia 1999, 70, 628.

4. Passador, E. A. P.; da Silva, M. F. G. F.; Rodrigues Filho, E.; Fernandes, J. B.; Vieira, P. C.; Pirani, J. R. Phytochemistry 1997, 45, 1533.

5. Arruda, A. C.; Vieira, P. C.; Fernandes, J. B. J. Braz. Chem. Soc. 1993, 4, 80.

6. Souza, J. P. I.; Arruda, A. C.; Arruda, M. S. P. Fitoterapia 1995, 66, 465.

7. Markham, K. R.; Mabry, T. J. In The Flavonoids, Harborne, J. B.; Mabry, T. J.: Mabry, H., Ed.; Academic Press; New York, 1975, Part 1, p 45.

8. Agrawal, P. K.; Rastogi, R. P. Heterocycles 1981, 16, 2181.

9. Herz, W.; Govindan, S. V.; Riess-Maurer, I.; Kreil, B. Wagner, H.; Farkas, L.; Strelisky, J. Phytochemistry 1980, 19, 669. 